\title{
$\mathrm{MR}$ 유체와 압전스택을 특징으로 하는 새로운 형태의 능도 엔진마운트 시스템
}

\section{A New Type of Active Engine Mount System Featuring MR Fluid and Piezostack}

\author{
이 동 영*.손 정 우*.최 승 복 \\ Dong-Young Lee, Jung Woo Sohn and Seung-Bok Choi
}

(2009년 3월 17일 접수 ; 2009년 5월 18일 심사완료)

Key Words : Engine(엔진), Hybrid Engine Mount(하이브리드 엔진마운트), MR Fluid(MR 유체), Piezostack Actuator(압전작동기), Optimal Control(최적제어)

\begin{abstract}
An engine is one of the most dominant noise and vibration sources in vehicle systems. Therefore, in order to resolve noise and vibration problems due to engine, various types of engine mounts have been proposed. This work presents a new type of active engine mount system featuring a magneto-rheological (MR) fluid and a piezostack actuator. As a first step, six degrees-of freedom dynamic model of an in-line four-cylinder engine which has three points mounting system is derived by considering the dynamic behaviors of MR mount and piezostack mount. In the configuration of engine mount system, two MR mounts are installed for vibration control of roll mode motion whose energy is very high in low frequency range, while one piezostack mount is installed for vibration control of bounce and pitch mode motion whose energy is relatively high in high frequency range. As a second step, linear quadratic regulator (LQR) controller is synthesized to actively control the imposed vibration. In order to demonstrate the effectiveness of the proposed active engine mount, vibration control performances are evaluated under various engine operating speeds(wide frequency range) and presented in time domain.
\end{abstract}

\section{1. 서 론}

오늘날 자동차 기술의 발달로 인한 차량의 경량 화, 엔진의 고출력화 추세는 종전보다 높은 소음과 진동 문제를 야기시키며, 이 소음과 진동은 승차감 에 큰 영향을 미치게 한다. 이러한 진동과 소음원 중의 하나는 엔진 구동계로 자동차 엔진에서 발생 하는 가스폭발과 불균형력은 차량의 소음과 진동의 큰 원인이 된다. 따라서 엔진의 움직임에 기인되는

† 교신저자; 정회원, 인하대학교 기계공학부

E-mail : seungbok@inha.ac.kr

Tel : (032)860-7319, Fax : (032)868-1716

* 인하대학교 기계공학과
자동차의 소음, 진동 문제를 해결하기 위해 엔진마 운트의 최적위치 결정과 우수한 성능의 엔진마운트 설계 및 제어를 위한 연구와 개발이 활발히 진행되 어 왔다(1 2).

엔진마운트는 엔진과 차체를 연결하는 부품으로 엔진의 지지와 함께 엔진에서 차체로 전달되는 진 동을 절연하는 역할을 한다. 기계류 진동절연에 널 리 적용되고 있는 고무마운트는 작은 강성과 댐핑 으로 인해 고주파수의 비공진주파수 대역에서는 우 수한 진동절연의 성능을 보이지만 공진주파수 대역 에서는 진동절연의 한계를 가지고 있다. 이러한 기 존 고무마운트의 단점을 보완하기 위하여 고안된 유체봉입마운트는 유체의 점성과 관성트랙을 이용 
하여 공진주파수 대역에서 우수한 진동절연 효과를 얻을 수 있다. 반면에 비공진주파수 대역에서는 진동 절연 성능이 저하된다 ${ }^{(3)}$. 고무마운트나 유체봉입마운 트와 같은 수동형 마운트의 한계를 극복하기 위하여 지능재료를 활용한 마운트에 대한 연구가 최근에 활 발히 진행되고 있다 ${ }^{(4-6)}$. 기존의 수동형 마운트를 기 본으로 하여 전달되는 진동 및 소음에 따라 지능재 료를 이용하여 능동적으로 제어력을 부가함으로써 진동 및 소음 절연성능을 크게 향상시킬 수 있는 반 능동마운트와 능동마운트에 대한 연구가 활발히 수 행되고 있다. MR 유체(magneto- rheological fluid)등 의 지능유체를 이용한 반능동형 엔진마운트는 유로 사이를 유동하는 유체를 이용하여 유동저항을 발생 시켜 진동절연을 위한 댐핑력을 발생시키며 힘을 직 접적으로 발생시키지는 못하지만 댐핑값을 조절 할 수 있어 효과적인 진동절연이 가능하고 특히 저주파 수 대역에서 뛰어난 진동절연 성능을 발휘한다 ${ }^{(7)}$. 그 리고 능동재료인 압전재료(piezoelectric material) 등을 이용한 능동형 엔진마운트는 높은 주파수 대 역에서 큰 힘을 발생시킬 수 있는 압전스택(piezostack)을 이용하여 시스템에 에너지를 공급함으로서 효과적인 진동절연이 가능하다 ${ }^{(8)}$. 하지만 지금까지 의 연구는 6-DOF 이상의 자유도로 거동되는 실제 시스템을 1-DOF 시스템으로 가정한 모델의 한계로 인해 여러 방향의 진동에 대해서는 효과적으로 제 어가 힘든 실정이다. 따라서 보다 효과적인 진동과 소음 절연을 위해서는 새로운 형태의 능동엔진마운 트 시스템의 모델링과 제어가 필요하다.

이 연구에서는 엔진마운트 시스템의 효과적인 진 동절연을 위해 $\mathrm{MR}$ 마운트와 압전스택 마운트를 고 려한 4실린더 4행정 가솔린 엔진마운트 시스템의 6 자유도 강체운동을 고려한 모델설정을 하였다. 일반 적으로 엔진의 운전속도가 저속일 때는 롤(roll)가진 토크가 가장 큰 에너지를 가지고 있고 고속으로 갈 수록 수직방향(vertical)가진의 에너지가 증가된다. 따라서 롤방향과 수직방향의 진동을 제어하기 위해 롤마운트로는 저주파수 대역에서 성능이 좋은 $\mathrm{MR}$ 엔진 마운트를 적용하였고 RH(right-hand)마운트로는 고주파수 대역에서 성능이 좋은 압전스택 마운트를 적용하였다. 그리고 $\mathrm{LQR}$ (linear quadratic regulator) 제어기를 이용한 시뮬레이션을 통해 제안된 엔진마 운트 시스템의 진동제어 성능을 평가하였다.

\section{2. 엔진의 동적 모델 및 해석}

\section{1 운동방정식}

일반적으로 차량에서 엔진마운트 시스템은 Fig. 1 과 같이 3 개의 병진운동 $(X, Y, Z)$ 과 3 개의 회전운동 $\left(\theta_{x}, \theta_{y}, \theta_{z}\right)$ 을 하는 6 자유도의 강체운동을 하며 3 점 지지 방식으로 엔진, $\mathrm{MR}$ 마운트 2개 $\left(f_{M R 1}, f_{M R 2}\right)$, 압전스택 마운트 1 개 $\left(f_{p i}\right)$ 로 구성되어 있다. 뉴톤 의 운동법칙을 적용하면 다음과 같은 운동방정식을 얻을 수 있다.

$$
[M] \ddot{x}_{G}+[C] \dot{x}_{G}+[K] x_{G}=\left\{U_{e}\right\}+\left\{U_{c}\right\}
$$

여기서 $[M],[C],[K],\left\{U_{e}\right\},\left\{U_{c}\right\}$ 는 각각 엔진마 운트 시스템의 질량행렬 $(6 \times 6)$, 댐핑행렬 $(6 \times 6)$, 강성 행렬(6×6), 엔진내부에서 발생하는 힘 $(6 \times 1)$, 능동마 운트의 제어력 $(6 \times 1)$ 을 뜻한다.([M], $[C],[K]$ 행렬 은 부록을 참조)

\section{2 엔진 가진력}

엔진 동력계의 가진력은 엔진의 피스톤과 커넥팅 로드의 왕복운동에 의한 상-하 방향의 관성력, 가스 폭발에 의한 토크, 피스톤 질량 관성에 의한 토크, 커넥팅로드에 의한 수정관성 토크로 나뉜다 ${ }^{(9,10)}$.

4사이클 4기통 인라인 엔진에서 엔진이 운동할 때 피스톤과 커넥팅로드의 왕복운동에 의한 상-하 방향의 관성력 $F_{z}$ 는 다음과 같이 나타낼 수 있다.

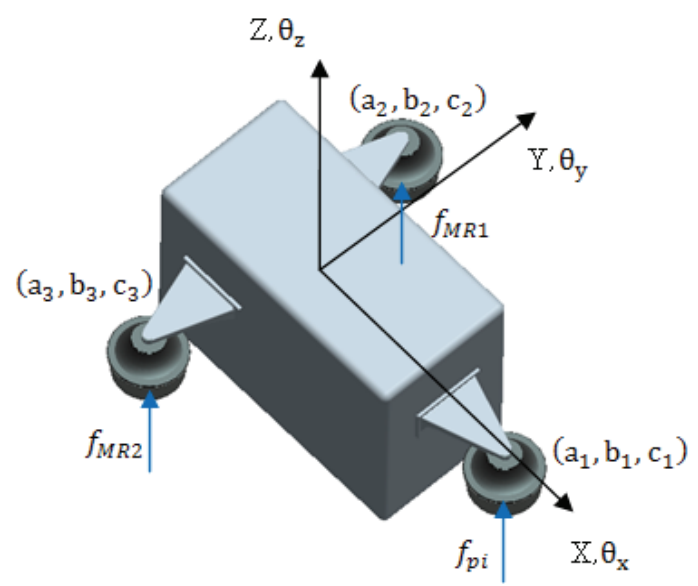

Fig. 1 Configuration of the engine mount system 


$$
F_{Z}=\frac{4 m_{p} r^{2} \omega^{2}}{l} \cos 2 \omega t
$$

여기서 $m_{p}$ 는 왕복질량, $r$ 은 크랭크 반경, $\omega$ 는 크 랭크 축의 회전속도, $l$ 은 커넥팅로드의 길이이다.

롤방향으로 작용하는 토크 $T_{t}$ 는 가스폭발에 의한 토크 $T_{P}$, 피스톤 질량 관성에 의한 토크 $T_{m}$, 커넥 팅로드에 의한 수정관성 토크 $T_{c}$ 의 합이 되고 다음 과 같이 구할 수 있다.

$$
\begin{aligned}
& T_{p}=A_{p} P\left(r \sin \omega t+\frac{r^{2}}{2 l} \sin 2 \omega t\right) \\
& T_{m}=-2 m_{P} r^{2} \omega^{2} \sin 2 \omega t \\
& T_{c}=-2 \frac{r^{2}}{l^{2}} \omega^{2}\left(l_{p} l_{q} m_{c}-I_{c}\right) \sin 2 \omega t \\
& T_{t}=T_{p}+T_{m}+T_{c}
\end{aligned}
$$

$A_{p}$ 는 피스톤의 면적, $P$ 는 피스톤의 가스압력, $l_{p}$ 는 크랭크 핀과 커넥팅로드의 질량중심과의 거리, $l_{q}$ 는 피스톤 핀과 커넥팅로드의 질량중심과의 거리, $m_{c}$ 는 커넥팅로드의 질량, $I_{c}$ 는 커넥팅로드의 관성 모멘트이다. $f_{x}, f_{y}, M_{y}, M_{z}$ 의 힘은 크지 않아 시스 템에 크게 영향을 미치지 못하므로 0 이라고 가정하 였다.

\section{3 마운트 제어력}

이 연구에서는 진동을 효과적으로 제어하기 위해 압전스택 마운트와 $\mathrm{MR}$ 마운트를 사용하였다. 각각 의 마운트에서 계산된 $f_{p i}, f_{M R}$ 등의 제어력이 시스 템에 공급되어 엔진의 진동을 절연하게 된다.

압전스택 마운트는 고무요소, 압전스택, 관성질량 으로 구성되며 고무마운트 내부에 압전스택과 관성 질량으로 이루어진 관성형작동기가 설치된 형태이다. 이 능동진동제어마운트의 기계적 모델은 Fig. 2 와 같 이 나타낼 수 있으며, 이로부터 능동진동제어마운트 시스템의 지배방정식은 다음과 같이 유도된다.

$$
\begin{aligned}
& m_{1} \ddot{x}_{1}-k_{p}\left(x_{2}-x_{1}\right)=-f_{a} \\
& m_{2} \ddot{x}_{2}+c_{r 1}\left(\dot{x}_{2}-\dot{x}_{0}\right)+k_{r 1}\left(x_{2}-x_{0}\right) \\
& =f_{a}-k_{p}\left(x_{2}-x_{1}\right) \\
& m_{2} \ddot{x}_{2}+c_{r 1}\left(\dot{x}_{2}-\dot{x}_{0}\right)+k_{r 1}\left(x_{2}-x_{0}\right)=-m_{1} \ddot{x}_{1}
\end{aligned}
$$

여기서 $f_{a}(=\delta V)$ 는 부하전압 $V$ 로 조절되는 압전스 택의 힘, $k_{r}, c_{r}$ 은 각각 고무요소의 강성과 댐핑, $m_{2}$ 는 압전스택 마운트에 부하되는 엔진의 질량이고 $m_{1}$ 은 관성질량이다. 이 질량은 압전스택에서 발생 되는 제어력을 구조물로 전달하기 위한 것이며, $x_{1}$ 은 이 관성질량의 변위이다. $x_{2}$ 는 마운트 상단의 변 위, $x_{0}$ 는 마운트 하단의 변위이다.

반면에 관성형작동기가 설치되지 않은 일반적인 고무마운트 모델의 경우의 운동방정식은 다음과 같 이 구할 수 있다.

$$
m_{2} \ddot{x}_{2}+c_{r 1}\left(\dot{x}_{2}-\dot{x}_{0}\right)+k_{r 1}\left(x_{2}-x_{0}\right)=0
$$

따라서 관성형작동기가 설치 된 시스템과 설치되 지 않은 시스템을 비교해 보면 관성형작동기에 의 해 추가되는 식은 다음과 같이 나타낼 수 있고 이 식을 관성형작동기가 설치된 압전스택 마운트의 제 어력이라고 말할 수 있다.

$$
f_{p i}=-m_{1} \ddot{x}_{1}
$$

이 연구에서 제안된 $\mathrm{MR}$ 마운트의 경우 상부는 고 무로 구성되어 있고 마운트 내부의 체적 변화시 $\mathrm{MR}$ 유체를 수용할 수 있는 챔버와 상-하부 챔버사이에

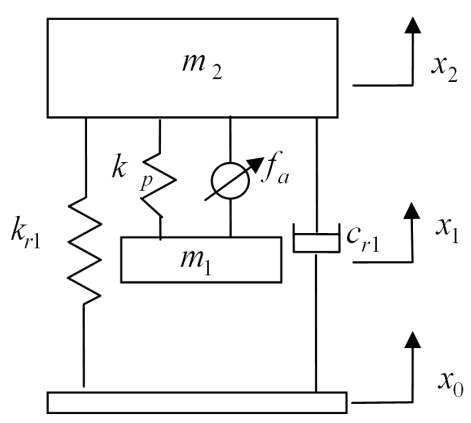

Fig. 2 Mechanical model of the piezostack mount

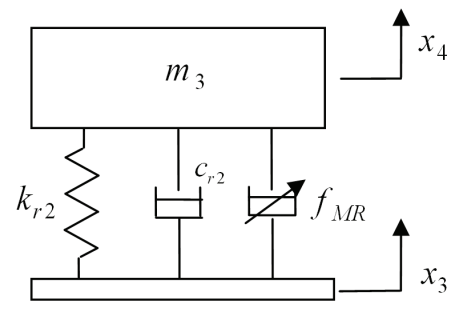

Fig. 3 Mechanical model of the MR mount 
실린더 모양의 $\mathrm{MR}$ 에 자극을 가할 수 있는 코일이 감긴 디스크로 구성된 유동모드와 전단모드가 혼합 된 형태의 반능동마운트이다. 이 $\mathrm{MR}$ 마운트의 기 계적 모델은 Fig. 3 과 같이 나타낼 수 있고 이로부 터 반능동진동제어마운트 시스템의 지배방정식은 다음과 같이 유도 할 수 있다.

$$
m_{3} \ddot{x}_{4}(t)+c_{r 2}\left(\dot{x}_{4}-\dot{x}_{3}\right)+k_{r 2}\left(x_{4}-x_{3}\right)=f_{M R}
$$

여기서 $m_{3}$ 는 $\mathrm{MR}$ 마운트 상단에 걸리는 엔진의 질 량이고 $x_{4}$ 는 마운트 상단의 변위, $x_{3}$ 는 마운트 하단 의 변위이고, $f_{M R}$ 이 $\mathrm{MR}$ 마운트의 제어력이 된다.

이 제어력은 다음과 같이 전단모드 $\left(f_{s}\right)$ 와 유동모 드 $\left(f_{f}\right)$ 에 의한 것으로 나누어진다.

$$
f_{M R}=f_{s}+f_{f}
$$

전단모드의 경우 $\mathrm{MR}$ 유체의 거동은 일반적으로 다음과 같은 빙햄 모델로 표현 할 수 있다.

$$
\begin{aligned}
& \tau=\tau_{y}+\eta \dot{\gamma} \\
& \tau_{y}(H)=\alpha H^{\beta}
\end{aligned}
$$

따라서 전단 모드에서 발생하는 힘은 다음과 같 이 구할 수 있다.

$$
f_{s}=\tau A_{c}
$$

여기서 $\tau$ 는 $\mathrm{MR}$ 유체의 전단응력을 나타내며, $A_{c}$ 는 접촉면적, $\eta$ 는 $\mathrm{MR}$ 유체의 기본점성 계수이고, $\dot{\gamma}$ 는 전단 속도비를 나타낸다. $\tau_{y}$ 는 $\mathrm{MR}$ 유체의 항복전단응력을 표현하는 것으로서, 자기장의 세기 (field intensity) $H$ 의 증가와 더불어 증가한다. 이 때, 비례상수 $\alpha$ 와 지수 $\beta$ 는 $\mathrm{MR}$ 유체의 항복응력 을 결정하는 고유 특성 값이다. 그리고 자기장의 세 기 $(H)$ 는 솔레노이드의 코일이 감긴 수 $(N)$ 과 솔레노 이드에 흐르는 전류 $(I)$ 를 그리고 자기장이 지나는 경로의 길이 $(L)$ 을 이용하면 다음과 같은 구할 수 있다.

$$
N I=H \times L
$$

또한 유동모드에 의해 발생하는 힘은 다음과 같 이 구할 수 있다.

$$
\begin{aligned}
f_{f} & =\left(\Delta P_{c}+\Delta P_{\eta}\right) A_{d} \\
& =\left(\frac{2 d}{L} \tau_{y}+\frac{12 \eta h}{L^{3} b} A_{d}\left(\dot{x}_{4}-\dot{x}_{3}\right)\right) A_{d} \\
& =\frac{2 d}{L} \alpha\left(\frac{N I}{L}\right)^{\beta} A_{d}+\frac{12 \eta h}{L^{3} b} A_{d}{ }^{2}\left(\dot{x}_{4}-\dot{x}_{3}\right)
\end{aligned}
$$

여기서 $\Delta P_{c}$ 는 자기장 부하시의 상-하부 챔버 사이 의 압력 차, $\Delta P_{\eta}$ 는 자기장 무부하시의 상-하부 챔 버 사이의 압력 차, $A_{d}$ 는 상부 챔버의 등가 피스톤 단면적, $b$ 는 디스크 중심에서 $\mathrm{MR}$ 유체가 흐르는 유동통로의 중간까지의 거리이다.

\section{3. 제어기 설계}

Fig. 4는 이 연구에서는 제안한 엔진마운트 시스 템의 제어블록선도를 나타낸 것이다. 엔진에서 발생 되는 가진력에 의해 발생하는 진동을 제어하기 위 해 $\mathrm{LQR}$ 되먹임 제어기를 도입하여 요구 제어력 $u_{c}\left(f_{p i}, f_{M R 1}, f_{M R 2}\right)$ 를 결정한다 ${ }^{(11)}$.

엔진마운트 시스템의 운동방정식을 통해 제안된 모델의 상태방정식은 다음과 같이 표현될 수 있다.

$$
\dot{x}=A x+B u_{c}+u_{e}
$$

여기서 상태변수는 각각 엔진무게중심의 병진운동 의 변위 $(X, Y, Z)$ 와 속도 $(\dot{X}, \dot{Y}, \dot{Z})$, 회전운동의 각 $\left(\theta_{x}, \theta_{y}, \theta_{z}\right)$ 과 각속도 $\left(\dot{\theta}_{x}, \dot{\theta}_{y}, \dot{\theta}_{z}\right)$ 이고 $A$ 는 시스템 행 렬, $B$ 는 입력 행렬이 되고, 제어입력 $u_{c}$ 와 엔진내부 에서 발생하는 힘 $u_{e}$ 는 다음과 나타낼 수 있다.

$$
\begin{aligned}
& u_{c}=\left[\begin{array}{llll}
f_{p i} & f_{M R 1} & f_{M R 2}
\end{array}\right]^{T} \\
& u_{e}=\left[\begin{array}{llllllllllllll}
0 & f_{x} & 0 & f_{y} & 0 & f_{z} & 0 & T_{t} & 0 & M_{y} & 0 & M_{z}
\end{array}\right]^{T}
\end{aligned}
$$

진동 제어를 위해 $\mathrm{LQR}$ 제어기를 사용하였으며 최적의 제어력을 얻기 위한 성능지수(performance index) $J$ 는 다음과 같이 설정하였다.

$$
J=\int_{0}^{\infty}\left(x^{T} Q x+u_{c}{ }^{T} R u_{c}\right) d t
$$




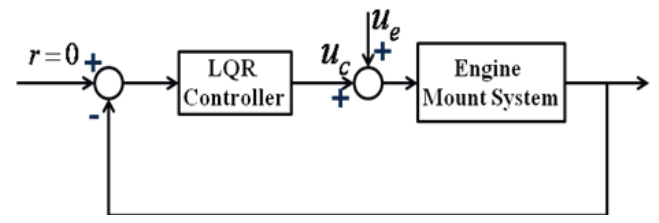

Fig. 4 Block diagram of LQR controller

요구 제어력 $u_{c}\left(f_{p i}, f_{M R 1}, f_{M R 2}\right)$ 는 다음과 같이 구할 수 있다.

$$
\begin{aligned}
& u_{c}=-G x \\
& G=\left(R+B^{T} P B\right) B^{T} P A
\end{aligned}
$$

여기서 $P$ 는 다음의 Riccati equation을 통하여 구할 수 있다.

$$
A^{T} P A-P-A^{T} P B\left(R+B^{T} P B\right)^{-1} B^{T} P A+Q=0
$$

\section{4. 결과 및 고찰}

이 연구에서는 앞에서 설계한 $\mathrm{LQR}$ 제어기를 사 용하여 엔진마운트 시스템에 대한 진동제어 성능을 컴퓨터 시뮬레이션을 통하여 평가하였고 그 결과를 Fig. 5 에서 Fig. 8에 나타내었으며 제어력은 2초 이 후 LQR 제어기를 통해 부가되었다. Fig. 5에는 엔 진의 공회전 $(750 \mathrm{rpm})$ 시의 수직방향과 롤방향의 제 어 성능을 나타내었고 이때 각각의 마운트에 입력 되는 제어입력은 Fig. 6에 나타나있다. 이 각각의 입 력이 마운트에 공급되어 마운트에서는 시스템에 제 어력을 공급하게 된다. Fig. 5의 결과를 살펴보면 수 직방향과 롤방향의 진동이 각각 $62 \%, 88 \%$ 감소한 것을 확인 할 수 있다. 또한 Fig. 7에 나타난 각각 의 마운트에 전달되는 힘를 살펴보면 $\mathrm{LQR}$ 제어기 가 작동 한 후에 각각의 마운트에 작용하는 힘이 줄어든 것을 확인 할 수 있다. 따라서 엔진마운트 시스템의 전체적인 진동이 감소했다는 것을 확인 할 수 있다.

Fig. 8에는 차량이 고속주행 할 때 평균 속도인 $2000 \mathrm{rpm}$ 에서의 진동제어 성능을 나타내었고 역시 수직방향과 롤방향의 진동이 감소함을 알 수 있다.

따라서 저주파수 대역과 고주파수 대역에서 압전

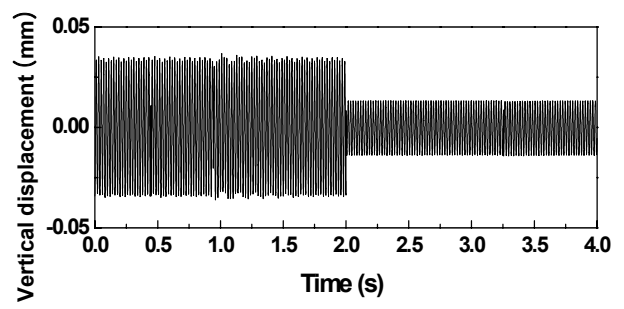

(a) Vertical displacement

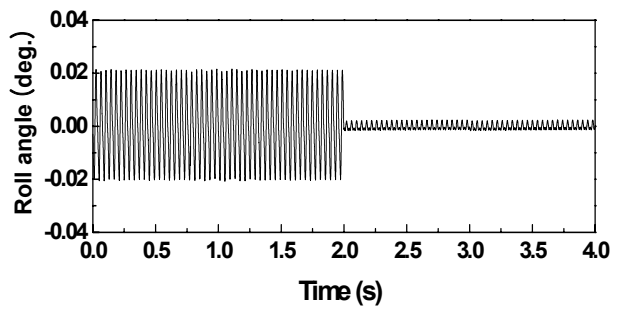

(b) Roll angle

Fig. 5 Vibration control response at $\mathrm{CG}(750 \mathrm{rpm})$

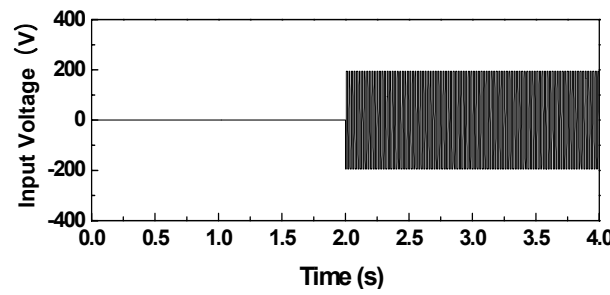

(a) Piezostack mount

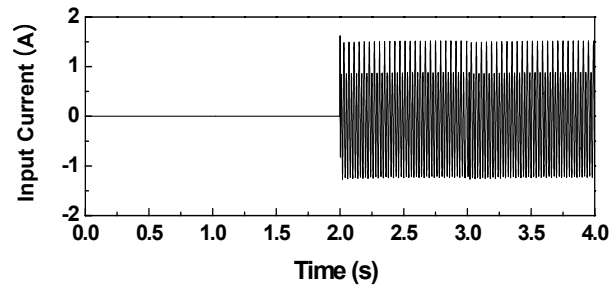

(b) MR mount 1

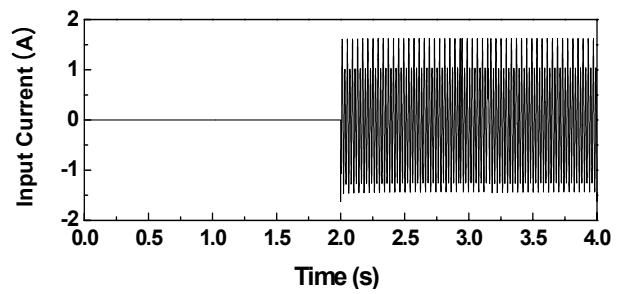

(c) MR mount 2

Fig. 6 Control input of each mount(750 rpm)

스택 마운트와 MR 마운트를 이용한 엔진마운트 시스 템의 진동이 $\mathrm{LQR}$ 제어를 통해 전체적으로 감소하여 


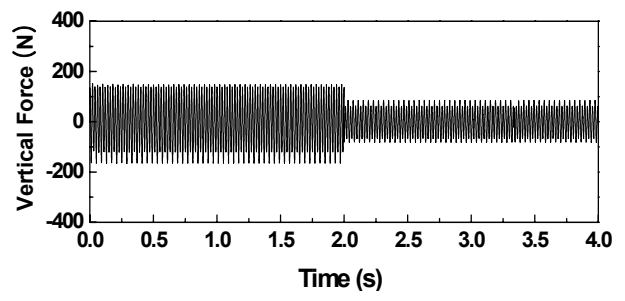

(a) Piezostack mount

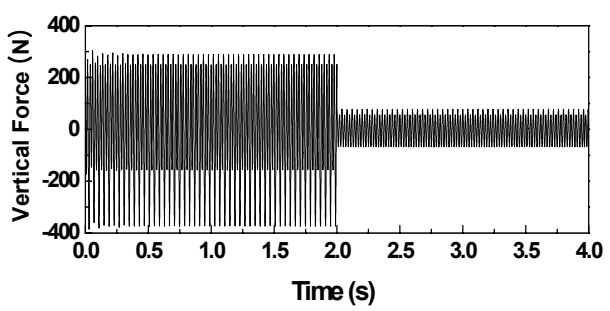

(b) MR mount 1

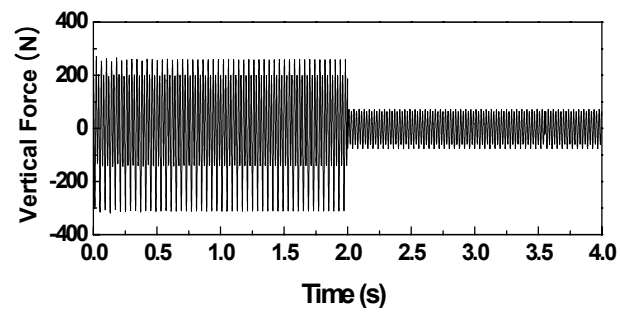

(c) MR mount 2

Fig. 7 Transmitted force at $750 \mathrm{rpm}$

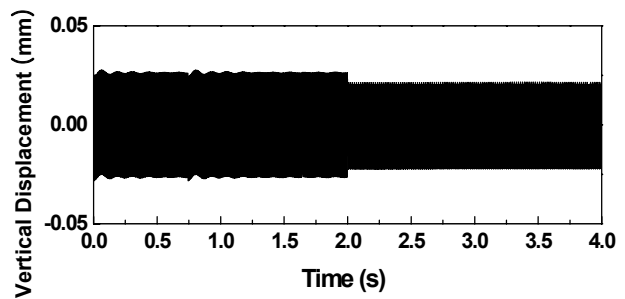

(a) Vertical displacement

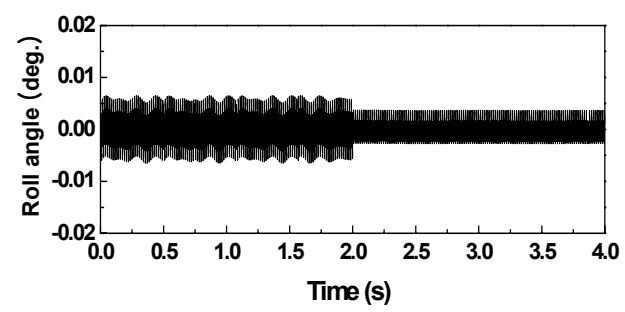

(b) Roll angle

Fig. 8 Vibration control response at $\mathrm{CG}(2000 \mathrm{rpm})$

제어 후에는 시스템의 진동이 안정적으로 변한 것 을 확인 할 수 있다.

\section{5. 결 론}

이 연구에서는 엔진의 진동을 감소시키기 위한 압전스택 마운트와 MR 마운트로 구성된 새로운 형 태의 엔진마운트 시스템을 제안하였다. 먼저, 엔진 마운트 시스템의 동적 모델을 해석 하였고 효과적 인 진동제어를 위해 최적 제어기의 하나인 $\mathrm{LQR}$ 제 어기를 이용하여 컴퓨터 시뮬레이션을 수행하였다. 시뮬레이션 결과를 통해 저주파수 대역과 고수파수 대역에서의 진동절연성능을 확인 하였고 엔진마운 트로 전달되는 힘 역시 감소함을 확인하였다.

향후 각 마운트의 실험을 통하여 얻은 제어력을 이용 HILS를 구성한 후 진동제어 성능을 고찰 할 예정이다.

\section{후 기}

이 연구는 지식경제부와 한국과학기술재단의 전 략기술인력양성사업으로 수행된 연구결과입니다.

\section{참 고 문 헌}

(1) Yu, Y., Naganathan, N. G., Dukkipati, R. V., 2001, "A Literature Review of Automotive Vehicle Engine Mounting Systens," Mechanism and Machine Theory, Vol. 36, pp. 123 142.

(2) Sakai, T., Iwahara, M., Shirai, Y., Hagiwara, I., 2001, "Optimum Engine Mounting Layout by Genetic Algorithm," SAE 2001-01-2810, pp. 1 7.

(3) Bernuchon, M., 1984, "A New Generation of Engine Mounts," SAE, 840259, pp. 230 236.

(4) Kim, S. H., Hong, S. R. and Choi, S. B., 2003, "Vibration Control of Flexible Beam Using Hybrid Mount," Transactions of the Korean Society for Noise and Vibration Engineering, Vol. 13, No. 7, pp. 524 531.

(5) Hong, S. R. and Choi, S. B., 2005, "Vibration Control of a Structural System Using Magnetorheological Fluid Mount," Journal of Intelligent Material System and Structures, Vol. 16, No. 11-12, pp. 931 936. 
(6) Yook, J. Y., Choi, S. B., Sung, K. G. and Moon, S. J., 2007, "Design of Hybrid Mount Using Rubber Element and Piezoelectric Actuator with Application to Vibration Control," Transactions of the Korean Society for Noise and Vibration Engineering, Vol. 17, No. 5, pp. 390 397.

(7) Takayoshi, K., Takafumi, F., Takayoshi, H., Takeo, A., Nobuyoshi, M., Satoru, A. and Kohtaro, T., 1997, "Active Vibration Control of Frame Structures with Smart Structures Using Piezoelectric Actuators(Vibration Control by Control of Bending Moments of Columns)," Smart Materials Structures, Vol. 6, pp. 448 456.

(8) Jolly, M. R., Bender, J. W. and Carlson, J. D., 1998, "Properties and Applications of Commercial
Magneto Rheological Fluids," Proceedings of the SPIE's 5th Annual Symposium on Smart Structures and Materials, Vol. 3327, pp. 262 275.

(9) Taylor, C, F, 1995, "The Internal Com- bustion Engine in Theory and Practice," Vol. 2, Chp. 8, M.I.T. Press.

(10) Seki, Y. and Suzuki, T., 2001, "How to Predict Powertrain Vibration at the Engine Mounting Points under Running Conditions," SAE 2001-011592, pp. 1 5.

(11) Choi, S. B., Sohn, J. W., Han, Y. M. and Kim, J. W., 2008, "Dynamic Characteristics of Threeaxis Active Mount Featuring Piezoelectric Actuators,' Journal of Intelligent Material Systems and Structures, Vol. 19, No. 9, pp. 1053 1066.

\section{Appendix}

(matrix for equations of motion and state space model matrix)

$$
\begin{aligned}
& {[M]=\left[\begin{array}{cccccc}
m & 0 & 0 & 0 & 0 & 0 \\
0 & m & 0 & 0 & 0 & 0 \\
0 & 0 & m & 0 & 0 & 0 \\
0 & 0 & 0 & I_{x x} & I_{x y} & I_{x z} \\
0 & 0 & 0 & I_{y x} & I_{y y} & I_{y z} \\
0 & 0 & 0 & I_{z x} & I_{z y} & I_{z z}
\end{array}\right], \quad[C]=\left[\begin{array}{cccccc}
c_{11} & 0 & 0 & 0 & c_{15} & c_{16} \\
0 & c_{22} & 0 & c_{24} & 0 & c_{26} \\
0 & 0 & c_{33} & c_{34} & c_{35} & 0 \\
0 & c_{24} & c_{34} & c_{44} & c_{45} & c_{46} \\
c_{15} & 0 & c_{35} & c_{45} & c_{55} & c_{56} \\
c_{16} & c_{26} & 0 & c_{46} & c_{56} & c_{66}
\end{array}\right],} \\
& {[K]=\left[\begin{array}{cccccc}
k_{11} & 0 & 0 & 0 & k_{15} & k_{16} \\
0 & k_{22} & 0 & k_{24} & 0 & k_{26} \\
0 & 0 & k_{33} & k_{34} & k_{35} & 0 \\
0 & k_{24} & k_{34} & k_{44} & k_{45} & k_{46} \\
k_{15} & 0 & k_{35} & k_{45} & k_{55} & k_{56} \\
k_{16} & k_{26} & 0 & k_{46} & k_{56} & k_{66}
\end{array}\right]} \\
& \mathrm{k}_{11}=\sum_{i=1}^{n} \mathrm{k}_{\mathrm{x}_{\mathrm{i}}}, \mathrm{k}_{22}=\sum_{i=1}^{n} \mathrm{k}_{\mathrm{y}_{\mathrm{i}}}, \mathrm{k}_{33}=\sum_{i=1}^{n} \mathrm{k}_{\mathrm{z}_{\mathrm{i}}}, \mathrm{k}_{44}=\sum_{i=1}^{n}\left(\mathrm{c}_{\mathrm{i}}{ }^{2} \mathrm{k}_{\mathrm{y}_{\mathrm{i}}}+\mathrm{b}_{\mathrm{i}}{ }^{2} \mathrm{k}_{\mathrm{z}_{\mathrm{i}}}\right), \mathrm{k}_{55}=\sum_{i=1}^{n}\left(\mathrm{a}_{\mathrm{i}}{ }^{2} \mathrm{k}_{\mathrm{z}_{\mathrm{i}}}+\mathrm{c}_{\mathrm{i}}{ }^{2} \mathrm{k}_{\mathrm{x}_{\mathrm{i}}}\right) \\
& \mathrm{k}_{66}=\sum_{i=1}^{n}\left(\mathrm{~b}_{\mathrm{i}}{ }^{2} \mathrm{k}_{\mathrm{x}_{\mathrm{i}}}+\mathrm{a}_{\mathrm{i}}{ }^{2} \mathrm{k}_{\mathrm{y}_{\mathrm{i}}}\right), \mathrm{k}_{15}=\sum_{i=1}^{n}\left(\mathrm{c}_{\mathrm{i}} \mathrm{k}_{\mathrm{x}_{\mathrm{i}}}\right), \mathrm{k}_{16}=\sum_{i=1}^{n}\left(-\mathrm{b}_{\mathrm{i}} \mathrm{k}_{\mathrm{x}_{\mathrm{i}}}\right), \mathrm{k}_{24}=\sum_{i=1}^{n}\left(-\mathrm{c}_{\mathrm{i}} \mathrm{k}_{\mathrm{y}_{\mathrm{i}}}\right), \mathrm{k}_{26}=\sum_{i=1}^{n}\left(\mathrm{a}_{\mathrm{i}} \mathrm{k}_{\mathrm{y}_{\mathrm{i}}}\right) \\
& \mathrm{k}_{34}=\sum_{i=1}^{n}\left(\mathrm{~b}_{\mathrm{i}} \mathrm{k}_{\mathrm{z}_{\mathrm{i}}}\right), \mathrm{k}_{35}=\sum_{i=1}^{n}\left(-\mathrm{a}_{\mathrm{i}} \mathrm{k}_{\mathrm{z}_{\mathrm{i}}}\right), \mathrm{k}_{45}=\sum_{i=1}^{n}\left(-\mathrm{a}_{\mathrm{i}} \mathrm{b}_{\mathrm{i}} \mathrm{k}_{\mathrm{z}_{\mathrm{i}}}\right), \mathrm{k}_{46}=\sum_{i=1}^{n}\left(-\mathrm{a}_{\mathrm{i}} \mathrm{c}_{\mathrm{i}} \mathrm{k}_{\mathrm{y}_{\mathrm{i}}}\right), \mathrm{k}_{56}=\sum_{i=1}^{n}\left(-\mathrm{b}_{\mathrm{i}} \mathrm{c}_{\mathrm{i}} \mathrm{k}_{\mathrm{x}_{\mathrm{i}}}\right)
\end{aligned}
$$




$$
\begin{aligned}
& \mathrm{c}_{11}=\sum_{i=1}^{n} \mathrm{c}_{\mathrm{x}_{\mathrm{i}}}, \mathrm{c}_{22}=\sum_{i=1}^{n} \mathrm{c}_{\mathrm{y}_{\mathrm{i}}}, \mathrm{c}_{33}=\sum_{i=1}^{n} \mathrm{c}_{\mathrm{z}_{\mathrm{i}}}, \mathrm{c}_{44}=\sum_{i=1}^{n}\left(\mathrm{c}_{\mathrm{i}}{ }^{2} \mathrm{c}_{\mathrm{y}_{\mathrm{i}}}+\mathrm{b}_{\mathrm{i}}{ }^{2} \mathrm{c}_{\mathrm{z}_{\mathrm{i}}}\right), \mathrm{c}_{55}=\sum_{i=1}^{n}\left(\mathrm{a}_{\mathrm{i}}{ }^{2} \mathrm{c}_{\mathrm{z}_{\mathrm{i}}}+\mathrm{c}_{\mathrm{i}}{ }^{2} \mathrm{c}_{\mathrm{x}_{\mathrm{i}}}\right) \\
& \mathrm{c}_{66}=\sum_{i=1}^{n}\left(\mathrm{~b}_{\mathrm{i}}{ }^{2} \mathrm{c}_{\mathrm{x}_{\mathrm{i}}}+\mathrm{a}_{\mathrm{i}}{ }^{2} \mathrm{c}_{\mathrm{y}_{\mathrm{i}}}\right), \mathrm{c}_{15}=\sum_{i=1}^{n}\left(\mathrm{c}_{\mathrm{i}} \mathrm{c}_{\mathrm{x}_{\mathrm{i}}}\right), \mathrm{c}_{16}=\sum_{i=1}^{n}\left(-\mathrm{b}_{\mathrm{i}} \mathrm{c}_{\mathrm{x}_{\mathrm{i}}}\right), \mathrm{c}_{24}=\sum_{i=1}^{n}\left(-\mathrm{c}_{\mathrm{i}} \mathrm{c}_{\mathrm{y}_{\mathrm{i}}}\right), \mathrm{c}_{26}=\sum_{i=1}^{n}\left(\mathrm{a}_{\mathrm{i}} \mathrm{c}_{\mathrm{y}_{\mathrm{i}}}\right) \\
& \mathrm{c}_{34}=\sum_{i=1}^{n}\left(\mathrm{~b}_{\mathrm{i}} \mathrm{c}_{\mathrm{z}_{\mathrm{i}}}\right), \mathrm{c}_{35}=\sum_{i=1}^{n}\left(-\mathrm{a}_{\mathrm{i}} \mathrm{c}_{\mathrm{z}_{\mathrm{i}}}\right), \mathrm{c}_{45}=\sum_{i=1}^{n}\left(-\mathrm{a}_{\mathrm{i}} \mathrm{b}_{\mathrm{i}} \mathrm{c}_{\mathrm{z}_{\mathrm{i}}}\right), \mathrm{c}_{46}=\sum_{i=1}^{n}\left(-\mathrm{a}_{\mathrm{i}} \mathrm{c}_{\mathrm{i}} \mathrm{c}_{\mathrm{y}_{\mathrm{i}}}\right), \mathrm{c}_{56}=\sum_{i=1}^{n}\left(-\mathrm{b}_{\mathrm{i}} \mathrm{c}_{\mathrm{i}} \mathrm{c}_{\mathrm{x}_{\mathrm{i}}}\right)
\end{aligned}
$$

$$
A=\left[\begin{array}{cccccccccccc}
0 & 1 & 0 & 0 & 0 & 0 & 0 & 0 & 0 & 0 & 0 & 0 \\
-\frac{k_{11}}{m} & -\frac{c_{11}}{m} & 0 & 0 & 0 & 0 & 0 & 0 & -\frac{k_{15}}{m} & -\frac{c_{15}}{m} & -\frac{k_{16}}{m} & -\frac{c_{16}}{m} \\
0 & 0 & 0 & 1 & 0 & 0 & 0 & 0 & 0 & 0 & 0 & 0 \\
0 & 0 & -\frac{k_{22}}{m} & -\frac{c_{22}}{m} & 0 & 0 & -\frac{k_{24}}{m} & -\frac{c_{24}}{m} & 0 & 0 & -\frac{k_{26}}{m} & -\frac{c_{26}}{m} \\
0 & 0 & 0 & 0 & 0 & 1 & 0 & 0 & 0 & 0 & 0 & 0 \\
0 & 0 & 0 & 0 & -\frac{k_{33}}{m} & -\frac{c_{33}}{m} & -\frac{k_{34}}{m} & -\frac{c_{34}}{m} & -\frac{k_{35}}{m} & -\frac{c_{35}}{m} & 0 & 0 \\
0 & 0 & 0 & 0 & 0 & 0 & 0 & 1 & 0 & 0 & 0 & 0 \\
0 & 0 & -\frac{k_{42}}{I_{x x}} & -\frac{c_{42}}{I_{x x}} & -\frac{k_{43}}{I_{x x}} & -\frac{c_{43}}{I_{x x}} & -\frac{k_{44}}{I_{x x}} & -\frac{c_{44}}{I_{x x}} & -\frac{k_{45}}{I_{x x}} & -\frac{c_{45}}{I_{x x}} & -\frac{k_{46}}{I_{x x}} & -\frac{c_{46}}{I_{x x}} \\
0 & 0 & 0 & 0 & 0 & 0 & 0 & 0 & 0 & 1 & 0 & 0 \\
-\frac{k_{51}}{I_{y y}} & -\frac{c_{51}}{I_{y y}} & 0 & 0 & -\frac{k_{53}}{I_{y y}} & -\frac{c_{53}}{I_{y y}} & -\frac{k_{54}}{I_{y y}} & -\frac{c_{54}}{I_{y y}} & -\frac{k_{55}}{I_{y y}} & -\frac{c_{55}}{I_{y y}} & -\frac{k_{56}}{I_{y y}} & -\frac{c_{56}}{I_{y y}} \\
0 & 0 & 0 & 0 & 0 & 0 & 0 & 0 & 0 & 0 & 0 & 1 \\
-\frac{k_{61}}{I_{z z}} & -\frac{c_{61}}{I_{z z}} & -\frac{k_{62}}{I_{z z}} & -\frac{c_{62}}{I_{z z}} & 0 & 0 & -\frac{k_{64}}{I_{z z}} & -\frac{c_{64}}{I_{z z}} & -\frac{k_{65}}{I_{z z}} & -\frac{c_{65}}{I_{z z}} & -\frac{k_{66}}{I_{z z}} & -\frac{c_{66}}{I_{z z}}
\end{array}\right],
$$

$$
B=\left[\begin{array}{ccc}
0 & 0 & 0 \\
0 & 0 & 0 \\
0 & 0 & 0 \\
0 & 0 & 0 \\
0 & 0 & 0 \\
\frac{1}{m} & \frac{1}{m} \\
0 & \frac{b_{2}}{I_{x x}} & \frac{b_{3}}{I_{x x}} \\
\frac{b_{1}}{I_{x x}} & 0 & 0 \\
0 & \frac{a_{2}}{I_{y y}} & -\frac{a_{3}}{I_{y y}} \\
\frac{a_{1}}{I_{y y}} & 0 & 0 \\
0 & 0 & 0 \\
0 & 0
\end{array}\right]
$$

